\title{
Investigation of Relationships between Self Efficacy and Scientific Epistemological Beliefs of Students in Physical Education and Sports
}

\author{
Sultan Yavuz Eroğlu ${ }^{\rtimes}$ \\ Metin Karayol ${ }^{2}$ (D) \\ 'High School of Physical Education and Sports, Siirt University, Turkey. \\ Email:Sultan-yvz@rwindowslive.com Tel: 00905594841305 \\ ${ }^{2}$ High School of Physical Education and Sport, Mus Alparslan University, Turkey. \\ Email:m.karayol@alparslan.edu.tr
}

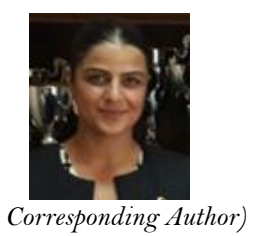

\section{Abstract}

This study aims to investigate the relationship between general self-efficacy and scientific epistemological beliefs of the students in the school of physical education and sports. The study group consists of 400 students (174 female, 226 male) in total. Personal information form created by researchers and "Scientific Epistemological Beliefs Scale" transcribed to Turkish by Acat, Gülçin, and Karadağ (2010) and "Self Efficacy Scale" transcribed to Turkish by Yeşilay (1996) has been used as a data collector in the study. In the analysis of data, the T-test has been used in the comparison of quantitative continuous data between two independent groups and the One Way Anova test has been used in the comparison of quantitative continuous data between more than two independent groups. Scheffe test has been used as the completive post hoc analysis to determine the differences after the Anova test. Pearson correlation test has been implemented between the continuous variables of the study. As a result of the study, it has been seen that there is a significant difference on behalf of the ones who are 20 years old and over informing information as one of the scientific epistemological sub-dimensions on behalf of the students of Bingöl University $(\mathrm{p}<0.05)$. It has been also seen that there is a significant difference on behalf of Ankara University students and females in the gender variable in general self-efficacy points $(p<0,05)$. It has not been seen that there is a significant difference in other variables $(p>0.05)$.

Keywords: Physical education, Sports, Epistemology, Epistemological Belief, Self Efficacy, Students.

Citation | Sultan Yavuz Eroğlu; Metin Karayol (2020). Investigation of Relationships between Self Efficacy and Scientific Epistemological Beliefs of Students in Physical Education and Sports. Asian Journal of Education and Training, 6(1): 93-98.

History:

: 18 November 2019

Revised: 30 December 2019

Accepted: 3 February 2020

Published: 27 February 2020

Licensed: This work is licensed under a Creative Commons

Attribution 30 License (cc)

Publisher: Asian Online Journal Publishing Group
Acknowledgement: Both authors contributed to the conception and design of the study.

Funding: This study received no specific financial support.

Competing Interests: The authors declare that they have no conflict of interests.

Transparency: The authors confirm that the manuscript is an honest, accurate, and transparent account of the study was reported; that no vital accurate, and transparent account of the study was reported; that no vital
features of the study have been omitted; and that any discrepancies from the features of the study have been omitted;
study as planned have been explained.

Ethical: This study follows all ethical practices during writing.

\section{Contents}

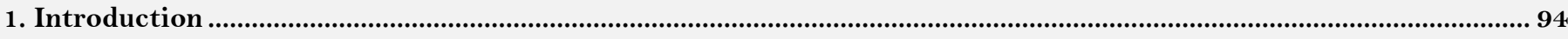

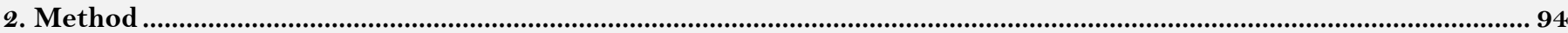

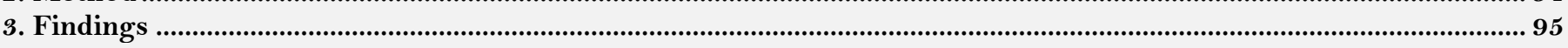

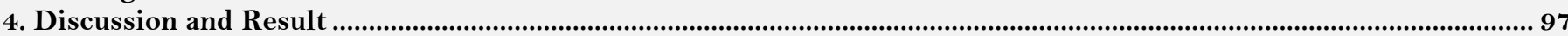

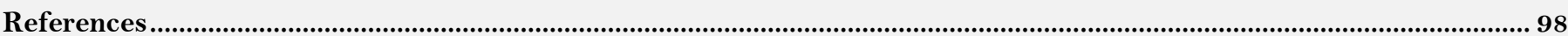




\section{Contribution of this paper to the literature}

This study contributes to the existing literature by examining the Investigation of Relations between Self Efficacy and Scientific Epistemological Beliefs of Students in Physical Education and Sports.

\section{Introduction}

Sport is an orderly implementing process of acquired behaviours by providing to develop and being acquired physical activity, main motoric skills, cognitive, psychosocial behaviours in individuals (Murathan \& Orak, 2017). Physical Education and Sports have also many benefits such as psychological, sociological, physical and physiological (Eroğlu \& Ersoy, 2019). In addition to that, both physical education and concept of sport which are shown as one of the most important social elements in recent days continue its existence as economic, social and dynamic (Reyhan, 2019). Information and technology are continuously speeding up with the effect of globalisation in today's world. As technology develops, it provides people different opportunities. The developments in technology affect educational systems like in every branch (Talha \& Kaya, 2016). Especially information has more importance in social and cultural areas with revealing the importance of our current information society. Under these living conditions, it has more importance to enable students to be raised as individuals who are absorbing science and scientific knowledge and using them in their life (Acat et al., 2010). The individuals in university years are trying to absorb science and knowledge to reach these goals for themselves. People should rely on their skills and knowledge to complete this effort successfully. Self-efficacy means self-judgment related to himself about the capacity of organising necessary activities and conducting them successfully to show a certain performance (Timur \& Taşar, 2013). According to another definition, self-efficacy means individuals' capacity to make sources and move and cognitive motivational and behavioural sources to control the events in their lives. Stored data with an increase in technology also has an increase. It is very important to identify crucial and required data. Epistemology which is becoming an important value in educational researches and questioning source, structure, trueness, validity, development and borders of knowledge comes into prominence. Therefore, reviewing the relation of epistemology and belief terms and components subjected to epistemology investigation is important in terms of becoming the meaning of educational researches apparent. In epistemology, it is important to consider the knowledge itself, question its systematic structure, deal the problems related to knowledge, look up to how information is true, legitimate, valid, look up to what causes knowledge, discourse the borders of knowledge (Demirel, 2007). The individuals perform a majority part of the preparation for life with outcomes in the classroom. Having developed an epistemological belief in this preparation process is becoming possible with the discussions related to how the teachers guiding them identify trueness, what sources of knowledge are, whether the knowledge is changed and the knowledge shows development or not (Evcim, 2010).

Sports education is an educational process involving speculative and operative education living. While the student is given necessary speculative information in this education process, it is important for a student to turn this information into skill in the execution area. One of the most important and prior conditions is that the quality of education is enough in the development of quality in sports education. To get the aims planned in sports education is based on the usage of international rules and methods of education. Organisational process supporting theory and operative information with experiences and following continuous innovations should be created when the only approach has been examined. To consider sports education separately from general education makes getting the required target impossible. The aim of education, in general, is to raise qualified human force with education. A qualified person is an individual having sufficiency in terms of social relations in society that he lives in and developed himself in terms of both physical and psychological. In this context, physical education and sports are extremely effective in raising qualified person (Kızılet, 2018). In this context, the idea that there is a relation between epistemological beliefs of physical education and sports students' self-sufficiency enables us to perform this study.

\section{Method}

\subsection{Study Group}

The study group consists of 400 students in total on voluntariness out of 226 males $(\% 56,5)$ and 174 females $(\% 43,5)$ students studying at Physical Education and Sports Vocational School of Higher Education in Bingöl, Ankara, Muş and Iğdır University.

\subsection{Data Collection Tool}

To determine the demographic information of the participants as a data collection tool, personal information form created by the researcher has been used (age, gender, department, branch, school, and sportsmen background)."Scientific Epistemological Beliefs Scale" transcribed to Turkish by Acat et al. (2010) has been used to measure the epistemological beliefs of the students. The scale consists of 25 articles and "Authority and Trueness" (1,5,12,15,16,20,23,24,25), "Knowledge Generation Process" (3,4,7,11,18), "Source of Knowledge" (6,10,13,14), "Reasoning" (2,21,22), and "Knowledge Variance" (9,17,19) sub-dimensions. In this research, it has been found out that the reliability of self-efficacy scale is high as Cronbach's Alpha=0,919.

"General Self Efficacy" scale transcribed to Turkish by Yeşilay (1996) has been used to measure the general self-efficacy of the students. The scale consists of 10 articles and one factor. In this research, the reliability of the scale has been found high as Cronbach's Alpha $=0,919$.

\subsection{Statistical Analysis of Data}

Data obtained from the study has been analysed by using SPSS (Statistical Package for Social Sciences) for Windows 22.0 program. Number, percentage, average, standard deviation have been used as descriptive statistical methods in data evaluation. 
T-test has been used in comparison of quantitative continuous data between two independent groups and One Way Anova test has been used in comparison of quantitative continuous data between more than two independent groups. Scheffe test has been used as the completive post hoc analysis to determine the difference after Anova test. Pearson correlation test has been implemented between continuous variables of the study.

\section{Findings}

In this section, there are findings obtained in the result of data analysis via the scales of the students participated into the study to solve problem of the study. Explanation and comments have been made based on the findings obtained.

\begin{tabular}{|c|c|c|}
\hline Groups & Frequency(n) & Percentage (\%) \\
\hline \multicolumn{3}{|l|}{ Age } \\
\hline $18-20$ & 203 & 50,7 \\
\hline Over 20 & 197 & 49,2 \\
\hline \multicolumn{3}{|l|}{ Gender } \\
\hline Female & 174 & 43,5 \\
\hline Male & 226 & 56,5 \\
\hline \multicolumn{3}{|l|}{ School } \\
\hline Bingöl & 100 & 25,0 \\
\hline Ankara & 99 & 24,8 \\
\hline Muş & 102 & 25,5 \\
\hline Iğdır & 99 & 24,8 \\
\hline \multicolumn{3}{|l|}{ Department } \\
\hline Education & 142 & 35,5 \\
\hline Coaching & 136 & 34,0 \\
\hline Management & 122 & 30,5 \\
\hline \multicolumn{3}{|l|}{ Branch } \\
\hline No Branch & 112 & 28,0 \\
\hline Team sports & 179 & 44,8 \\
\hline Individual Sports & 109 & 27,3 \\
\hline \multicolumn{3}{|c|}{ Sportsmen Background } \\
\hline 5 Years and below & 222 & 55,5 \\
\hline 5 Years and over & 178 & 44,5 \\
\hline
\end{tabular}

Table 1 shows that the students have been dispersed according to age; 203 of them are 18-20 years old (\%50,7), and 197 of them are over $20(\% 49,2)$. The students have been dispersed according to gender; 174 of them are female $(\% 43,5)$, and 226 of them are male $(\% 56,5)$. The students have been dispersed according to school ; 100 of them are from Bingöl (\%25,0), 99 of them are from Ankara (\%24,8), 102 of them are from Muş (\%25,5), and 99 of them are from Iğdır $(\% 24,8)$. The students have been dispersed according to department; 142 of them are from education (\%35,5), 136 of them are from coaching (\%34,0), 122 of them are from management (\%30,5). The students have been dispersed according to branch; 112 of them are from no branch (\%28,0), 179 of them are from team sports $(\% 44,8)$, and 109 of them are from individual sports $(\% 27,3)$. The students have been dispersed according to sportsmen background; 222 of them are 5 years and below $(\% 55,5)$ and 178 of them are 5 years and over $(\% 44,5)$.

Table-2. The averages of scientific epistemological beliefs and self efficacy sub-dimensions

\begin{tabular}{l|c|c|c|c|c}
\multicolumn{7}{c|}{ Table-2. The averages of scientific epistemological beliefs and self efficacy sub-dimensions. } \\
\hline Sub-dimensions of the scale & $\mathbf{N}$ & Average & Mr & Min. & Max. \\
\hline Authority and Trueness & 400 & 3,203 & 0,949 & 1,000 & 5,000 \\
\hline Knowledge Generation Process & 400 & 3,829 & 0,846 & 1,000 & 10,670 \\
\hline Source of Knowledge & 400 & 3,341 & 0,942 & 1,000 & 5,000 \\
\hline Reasoning & 400 & 3,860 & 0,866 & 1,000 & 5,000 \\
\hline Knowledge Variance & 400 & 3,713 & 0,943 & 1,000 & 7,000 \\
\hline Scientific Epistemological Beliefs General & 400 & 3,515 & 0,669 & 1,000 & 5,600 \\
\hline Self Efficacy & 400 & 3,619 & 0,999 & 1,000 & 5,000 \\
\hline
\end{tabular}

Table 2 reported that the "authority and trueness" average of the students is medium 3,203 $\pm 0,949$ (Min=1; Max=5), "knowledge generation process" average is high 3,829 $\pm 0,846$ (Min=1; Max=10.67), "source of knowledge" average is medium 3,341 $\pm 0,942$ (Min=1; Max=5), "reasoning "average is high 3,860 $\pm 0,866$ (Min=1;

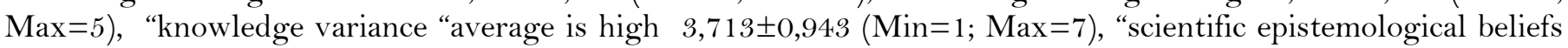
general" average is high 3,515 $\pm 0,669$ (Min=1; Max=5.6), "self-efficacy" average is high 3,619 $\pm 0,999$ (Min=1; $\operatorname{Max}=5)$. 
Table-3. Correlation analysis between scientific epistemological beliefs and self-efficacy scores based on sub-dimensions.

\begin{tabular}{|c|c|c|c|c|c|c|c|c|}
\hline Sub-Dimension & Correlation & $\begin{array}{l}\text { Authority } \\
\text { and } \\
\text { Trueness }\end{array}$ & $\begin{array}{c}\text { Knowledge } \\
\text { Generation } \\
\text { Process }\end{array}$ & $\begin{array}{c}\text { Source of } \\
\text { Knowledge }\end{array}$ & Reasoning & $\begin{array}{c}\text { Knowledge } \\
\text { Variance }\end{array}$ & \begin{tabular}{|c|}
\multicolumn{1}{|c|}{ Scientific } \\
Epistemological \\
Beliefs General \\
\end{tabular} & $\begin{array}{c}\text { Self } \\
\text { Efficacy }\end{array}$ \\
\hline $\begin{array}{l}\text { Authority and } \\
\text { Trueness }\end{array}$ & $\mathrm{p}$ & 0,000 & & & & & & \\
\hline \multirow{2}{*}{$\begin{array}{c}\text { Knowledge } \\
\text { Generation Process }\end{array}$} & $\mathrm{r}$ & $0,242^{*} *$ & 1,000 & & & & & \\
\hline & $\mathrm{p}$ & 0,000 & 0,000 & & & & & \\
\hline $\begin{array}{l}\text { Source of } \\
\text { Knowledge }\end{array}$ & $\mathrm{p}$ & 0,000 & 0,000 & 0,000 & & & & \\
\hline \multirow{2}{*}{ Reasoning } & $r$ & 0,167 ** & $0,564 * *$ & $0,264^{* *}$ & 1,000 & & & \\
\hline & $\mathrm{p}$ & 0,001 & 0,000 & 0,000 & 0,000 & & & \\
\hline \multirow{2}{*}{$\begin{array}{c}\text { Knowledge } \\
\text { Variance }\end{array}$} & $\mathrm{r}$ & $0,241 * *$ & $0,598 * *$ & $0,282^{* *}$ & $0,592^{* *}$ & 1,000 & & \\
\hline & $\mathrm{p}$ & 0,000 & 0,000 & 0,000 & 0,000 & 0,000 & & \\
\hline Self-Efficacy & $\mathrm{p}$ & 0,441 & 0,056 & 0,639 & 0,014 & 0,013 & 0,277 & 0,000 \\
\hline
\end{tabular}

Note: $*<0,05 ; * *<0,01$.

Table-4. The condition of differentitation of scientific epistemological beliefs and self efficacy points according to descriptive features based on demographic features.

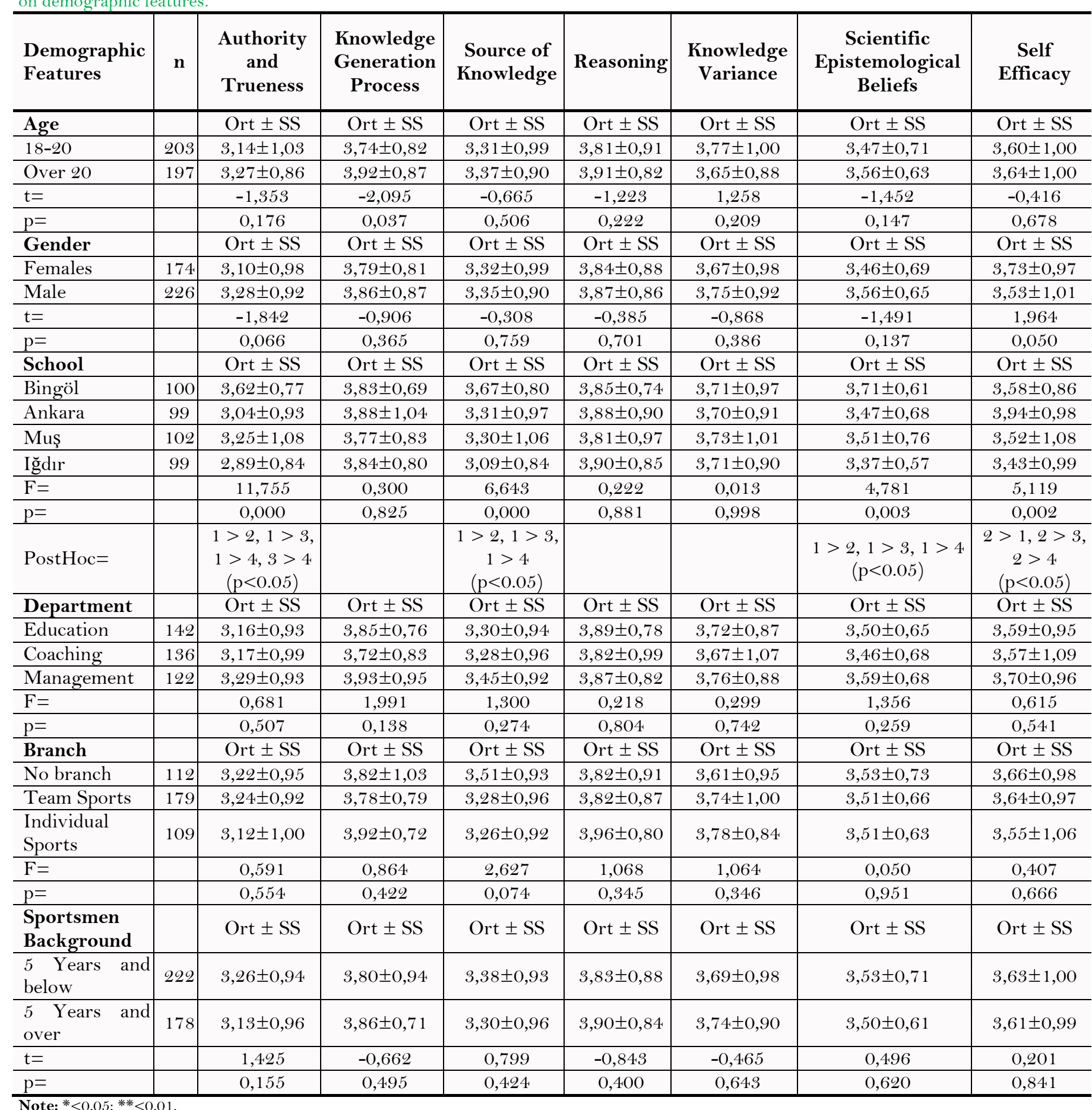

Table 3 when correlation analysis has been examined that it has been found that there is a positive relation between authority and trueness and knowledge generation process $r=0.242(p=0,000<0.05)$, Source of knowledge and reasoning $r=0.746(p=0,000<0.05)$, Source of knowledge and knowledge generation process $r=0.318$ 
$(p=0,000<0.05)$, Reasoning and authority and trueness $r=0.167 \quad(p=0,001<0.05)$, Reasoning and knowledge generation process $r=0.564(p=0,000<0.05)$, Reasoning and source of knowledge $r=0.264 \quad(p=0,000<0.05)$, Knowledge Variance and authority and trueness $r=0.241(p=0,000<0.05)$, Knowledge Variance and knowledge generation process $\mathrm{r}=0.598 \quad(\mathrm{p}=0,000<0.05)$, Knowledge Variance and source of knowledge $\mathrm{r}=0.282$ $(p=0,000<0.05)$, Knowledge Variance and reasoning $r=0.592 \quad(p=0,000<0.05)$, Scientific epistemological beliefs general and authority and trueness be $r=0.819 \quad(p=0,000<0.05)$, Scientific Epistemological Beliefs General and knowledge generation process $r=0.687 \quad(p=0,000<0.05)$, Scientific Epistemological Beliefs General and source of knowledge $r=0.791 \quad(p=0,000<0.05)$, Scientific Epistemological Beliefs General and reasoning $r=0.571$ $(p=0,000<0.05)$, Scientific Epistemological Beliefs General and knowledge variance $=0.629 \quad(p=0,000<0.05)$, Self efficacy and reasoning $\mathrm{r}=0.123(\mathrm{p}=0,014<0.05)$, self-efficacy and knowledge variance $\mathrm{r}=0.123 \quad(\mathrm{p}=0,013<0.05)$. The relations between other variables are not statistically significant ( $\mathrm{p}>0.05)$.

Table 4 shows that it has been found out that the points of knowledge generation process of the ones 18-20 years old $(\mathrm{x}=3,74)$ are lower than the ones over 20 years old $(\mathrm{x}=3,919)$. The authority and trueness, source of knowledge, reasoning, knowledge variance, scientific epistemological beliefs general and self-efficacy points of the students do not show a significant difference according to age variable $(\mathrm{p}>0.05)$.

It has been found out that self-efficacy points of females $(x=3,730)$ are higher than the self-efficacy points of males $(t=1,964 ; p=0.05<0.05)$. The authority and trueness, knowledge generation process, source of knowledge, reasoning, knowledge variance, Scientific Epistemological beliefs general points of the students do not show a significant difference $(\mathrm{p}>0.05)$. The authority and trueness points of the students show a significant difference according to school variable $(\mathrm{F}=11,755 ; \mathrm{p}=0<0.05)$. The reason of the difference is the fact that the authority and trueness points of the ones whose school in Bingöl are higher than the ones whose school in Ankara $(p<0.05)$. The authority and trueness points of those whose school is located in Bingöl are higher than those in Muş ( $<<0.05$ ). The authority and trueness points of those whose school is located in Bingöl are higher than those in Iğdır $(p<0.05)$. The authority and trueness points of those whose school is located in Muş are higher than those in Iğdır $(\mathrm{p}<0.05)$. The source of knowledge points of the students show a significant difference according to school variable $(\mathrm{F}=6,643 ; \mathrm{p}=0<0.05)$. The reason of the difference is the fact that the source of knowledge points of those whose school is in Bingöl are higher than those in Ankara $(p<0.05)$. The source of knowledge points of those whose school is in Bingöl are higher than those in Muş $(p<0.05)$. The authority and trueness points of those whose school is in Bingöl are higher than those in I Ĭdır $(\mathrm{p}<0.05)$. The Scientific Epistemological beliefs general points of the students show a significant difference $(\mathrm{F}=4,781 ; \mathrm{p}=0.003<0.05)$. The reason of the difference is the fact that the scientific epistemological beliefs general points of the ones whose school in Bingöl are higher than the ones whose school in Ankara $(\mathrm{p}<0.05)$. The scientific epistemological beliefs general points of those whose school is in Bingöl are higher than those in Muş $(p<0.05)$. The scientific epistemological beliefs general points of those whose school is in Bingöl are higher than those in Iğdır $(\mathrm{p}<0.05)$. The self-efficacy points of the students show a significant difference $(\mathrm{F}=5,119 ; \mathrm{p}=0.002<0.05)$. The reason of the difference is the fact that the self-efficacy points of the ones whose school in Ankara are higher than the ones whose school in Bingöl $(p<0.05)$. The self-efficacy points of the ones whose school in Ankara are higher than those whose school is in Muş $(p<0.05)$. The self-efficacy points of those whose school is in Ankara are higher than those in I $\breve{g} \operatorname{dır}(\mathrm{p}<0.05)$.

The knowledge generation process, reasoning, knowledge variance points of the students do not show a significant difference according to department variable ( $p>0.05)$.

The authority and trueness, knowledge generation process, source of knowledge, reasoning., knowledge variance, scientific epistemological beliefs general, self-efficacy points of the students do not show a significant difference according to department variable ( $p>0.05)$. The authority and trueness, knowledge generation process, source of knowledge, reasoning., knowledge variance, scientific epistemological beliefs general, self-efficacy points of the students do not show a significant difference according to branch variable ( $p>0.05)$. The authority and trueness, knowledge generation process, source of knowledge, reasoning., knowledge variance, scientific epistemological beliefs general, self-efficacy points of the students do not show a significant difference according to sportsmen background ( $\mathrm{p}>0.05)$.

\section{Discussion and Result}

The sources related to our subject or having close relation in the direction of our study have been reached. In our study, when we look whether the general self efficacy points and scientific epistemological beliefs general sub dimensions differ in gender, age, department, school, branch, sportsmen background, variables or not, the result has been found on behalf of the ones who are 20 years old and over in knowledge generation which is a scientific epistemological sub dimension of the participants $(\mathrm{p}<0.05)$. In the adaptation period of the students starting university, they start to learn how to reach knowledge. Therefore, it confirms our study that the students over 20 years old are more aware in terms of knowledge generation than the ones below 20 years old. Besides the study (Bayrak, Cinar, Coban, \& Coşkuner, 2013) supporting our findings and having a significant difference between epistemological beliefs and age in literature, it has been seen that there are studies having contrast findings (Cağlayan \& Mehtap, 2010; Güngör \& Yenel, 2017; Paulsen \& Wells, 1998). When we examine the analysis results of the study conducted, while it has been reported that epistemological beliefs of physical education and sports teacher candidates do not show a significant difference according to age ranges, it has been stated that the epistemological beliefs of physical education and sports teacher candidates develop as the age increases according to data obtained (Güngör., 2016; Yılmaz, 2007). In our other finding, it has been seen that there is a significant difference on behalf of university students of Bingöl in terms of authority and trueness which is a sub dimension of scientific epistemological beliefs general belief general according to source of knowledge and school variable $(\mathrm{p}<0.05)$. In the studies in which the students from different universities have participated in literature, it shows contrast to our findings (Cağlayan \& Mehtap, 2010; Güngör \& Yenel, 2017). Epistemological beliefs are generally subjective beliefs related to how knowing and learning are performed and the individuals' thought of what knowledge is Sander (2005). 
On the other hand in our study, it has not been seen that there is a significant difference between the variables of gender, department, branch, sportsmen background and scientific epistemological sub dimensions ( $\mathrm{p}>0.05)$. In literature, the studies parallel to our findings are available (Biçer, Er, \& Ozel, 2013; Cağlayan \& Mehtap, 2010; Karabulut \& Ulucan, 2012; Keskin \& Aydın, 2010; Tailor, 2005). The reason that mentioned variables in our study and the difference is not the same is because it is considered that the individuals born and raised in east have studied at the same place and it can be said that they are in the same cultural and social structure. At the same time we are of opinion that it is necessary to study with different sample groups and in different regions according to obtained data. It has been seen that there is a significant difference on behalf of females and the students of Ankara University in gender variable in general self efficacy points $(\mathrm{p}<0.05)$. However, it has not been seen that there is a significant difference in department, sportsmen background, age and branch variables $(\mathrm{p}>0.05)$. There are also studies showing parallelism to our study in terms of gender (Omur \& Cubukcu, 2017) and not showing parallelism (Bozkurt, 2013; Duman, 2018; Yeşilyurt, 2013). Although we live in a patriarchal society, we aware that females are more willing to reach knowledge and source of knowledge compared to males because they desire to exist more in society and especially their personal efforts. In the correlation analysis result conducted; it has been found that there is relation between scientific epistemological scale sub dimensions in a positive way. It has been found that there is a positive relation between reasoning and self efficacy and self efficacy and knowledge variance. The relations between other variables are not statistically significant $(p>0.05)$. Our hypothesis that there is a positive and high level relation between epistemological beliefs of the students in school of physical education and sports and self efficacy has been accepted partly and it is guiding to next studies to be conducted with different sample groups.

\section{References}

Acat, M. B., Gülçin, T., \& Karadağ, E. (2010). Scientific epistemological beliefs scale: Adaptation to Turkish culture, language validity and analysis of factor structure. Turkish Journal of Science Education, 7(4), 67-69.

Bayrak, E., Cinar, V., Coban, B., \& Coşkuner, Z. (2013). Investigation of scientific epistemological beliefs of teacher candidates of physical education and sports school and teacher candidates of education faculty in terms of different variables. The Journal of Academic Social Science Studies, 6(2), 1817-1828.

Biçer, B., Er, H., \& Ozel, A. (2013). The relationship between pre-service teachers' epistemological beliefs and educational philosophies adopted. Theory and Practice in Education Journal of Theory and Practice in Education, 9(3), 230-249.

Bozkurt, T. (2013). Examination of teacher self-efficacy of candidates of physical education teachers. Master Thesis, Gazi University, Institute of Education Departments, Ankara.

Cağlayan, H. S., \& Mehtap, B. (2010). Investigation of epistemological beliefs of university women's futsal team athletes in terms of some variables. Niğde University Journal of Physical Education and Sports Sciences, 4(1), 37-47.

Demirel, I. (2007). Epistemological world systems analysis. Doctoral Thesis, Dokuz Eylül University Institute of Social Sciences.

Duman, T. (2018). Physical education and sports teacher candidates' attitudes towards teaching profession and academic self-efficacy levels. Master Thesis, Hitit University Institute of Health Sciences, Corum.

Eroğlu, E., \& Ersoy, A. (2019). Examination of learned strength levels of physical education and sports school students according to some variables. International Journal of Multidisciplinary Academic Research, 6(2), 68-75.

Evcim, I. (2010). The relationship between epistemological beliefs and levels of using science gains in their daily lives and academic Achievements of elementary school students. Master's Thesis, Marmara University, Istanbul.

Güngör, N. B., \& Yenel, F. (2017). Investigation of the relationship between epistemological beliefs and leadership characteristics of physical education and sports teaching department students. Atatürk University Journal of Physical Education and Sports Sciences, 19(2), 39-55.

Güngör., B. N. (2016). Investigation of the relationship between epistemological beliefs and leadership characteristics of physical education teacher candidates. Master Thesis, Gazi University Institute of Educational Sciences, Ankara.

Karabulut, E. O., \& Ulucan, H. (2012). Investigation of scientific epistemological beliefs of physical education teacher candidates in terms of different variables. Journal of Sports and Performance Research, 3(2), 29-44.

Keskin, I., \& Aydın, M. (2010). Investigation of prospective teachers' scientific epistemological beliefs in terms of some variables: An example of Mathematics and social studies teaching. Journal Of Education And Humanities: Theory And Practice, 7(13), 29-48.

Kizılet, T. (2018). The effect of drama and diction teaching on vocational proficiency of sports trainee students. Master Thesis, Istanbul.

Murathan, T., \& Orak, G. (2017). Children's games and sports culture in Ardahan. Ankara: Sports Publishing House and Bookstore.

Omur, M., \& Cubukcu, F. (2017). Examining the Relationship between the use of self-regulation strategies and motivation levels of foreign language students. International Journal of Contemporary Educational Research, 3(2), 18-33.

Paulsen, M. B., \& Wells, C. T. (1998). Domain differences in the epistemological beliefs of college students. Research in Higher Education, $39(4), 365-384$.

Reyhan, S. (2019). Examination of self-esteem, anxiety and professional satisfaction levels according to the referee experience of football referees working in professional leagues (Example of 11 th Region). KOSBED, 37(1), 161-172.

Sander, P. (2005). Researching our students for more effective university teaching. Electronic Journal of Research in Educational Psychology, $3(1), 113-130$.

Tailor, A. R. (2005). A research on scientific epistemological beliefs of university students. Afyon Kocatepe University Journal of Social Sciences, 2, 309-310.

Talha, M., \& Kaya, O. (2016). Evaluation of sports trainers perceptions on computer aided education related to the attitudes toward learning. Universal Journal of Educational Research, 4(2), 416-42 1. Available at: https://doi.org/10.13189/ujer.2016.040215.

Timur, B., \& Taşar, M. F. (2013). Adaptation of the self-efficacy belief scale for the use of computers in science education into Turkish. Journal of Turkish Science Education, $10(3), 59-72$.

Yeşilay, A. (1996). Generalized self-authority expectation, internet address. Retrieved from: http://userpage.fu-berlin.de/ health/turk.htm. [Accessed 22.02.2020].

Yeşilyurt, E. (2013). Teacher candidates' self-efficacy perceptions. Journal of Electronic Social Sciences, 12(45), 88-104.

Yılmaz, A. (2007). The relationship between epistemological beliefs of nursing students and locus of control. Unpublished Master Thesis, Istanbul University Institute of Health Sciences Nursing Education Department, Istanbul. 